\title{
Impact of Informal Groups on Organisational Performance
}

\author{
Dr. Cross Ogohi Daniel
}

Department of Business Administration Nile University Of Nigeria, Abuja

\begin{abstract}
The purpose of this study is to investigate the impact of informal groups on organizational performance. Informal groups are a very powerful social network which are constructed in response to and through actions of their members, informal groupings when viewed on the degree of their being informal, creates a managerial burden informally for managers who require additional competences to manage their activities. Informal groups exist to achieve group interest which may not necessarily be in tandem with the overall goals of the organization. The aim of this study is to identify why employees engage in informal groups. A survey research design was adopted and copies of questionnaire were administered on 319 employees of the selected construction companies, using disproportionate stratified sampling technique. The data collected were analyzed using Pearson product moment correlation. The questionnaire was validated using content validity. The reliability of the questionnaire was confirmed by determining the correlation coefficient of the data collected at two different periods. The study discovered informal groups has a significant effect on employee performance, there is a significant relationship between informal groups and their characteristics, there is a significant relationship between informal groups and selfconfidence in Nigerian construction firms and Informal groups has significant influence on organizational performance in Nigeria.
\end{abstract}

Keywords: Informal, Groups, Formal, Performance, Self-confidence and Organization.

\subsection{Introduction}

In today's organisation, where productivity and efficiency demand collaboration within and across functional, physical and hierarchical boundaries, collaboration in employee networks has become critical to innovation, and to both individual and company performance. This does not apply to companies only but also to institutions such as schools. According to Parker and Cross (2014), most managers have little understanding of how their employees actually interact to get work done. In fact, institutional charts fail to reveal the often hidden social networks that truly drive or hinder an individual's performance.

Parker and Cross (2014) observe that in achieving institutional mission and objectives, informal groups emerge within the institute which might not be organized around a set of objectives. Mullins (2010) articulates that informal groups are very powerful social networks which are constructed in response to and through actions of their members.

Mullins (2010) further articulates that managers and supervisors frequently face problems due to failure to recognize that within every organisation there are often informal group pressures that influence and regulate individual behavior. Informal groups formulate an implicit code of ethics or undesirable set of standards establishing acceptable behaviors for a group of employees.

According to Greenberg (2010), Informal groups can occur in an organisation as a result of the mutually shared interest of the individuals. The concept of informal groups in the Construction sector plays a vital role due to the nature of jobs and the working environment which needs commitment by the employees so as to keep standards. Most leaders have failed to appreciate the existence of informal groups and these calls for the leaders to investigate the reasons for their existence. Therefore, in light of the problems highlighted above, this study sought to investigate the effects of informal groups on employee performance. There is fast growing literature with empirical evidence on informal groups at work (Gillas 2007). 
While this thinking subsists, Van, et al (2011) are of the view that informal groupings when viewed on the degree of their being informal, creates a managerial burden informally for managers who require additional competences to manage their activities. Informal groups exist to achieve group interest which may not necessarily be in tandem with the overall goals of the organisation. This goal diversity often times creates conflict of interest which managers must resolve. The inability of organizational managers to cope with the ever present interest of informal groups will create a dysfunctional work climate.

Reitz (2007) espoused establishing viable relationships among work members that are recognized representatives of social work teams that are organizational goal directed. However, they expressed a conceptual skepticism in examining the similarity between work teams and informal group. Their skepticisms were on the premise that informal groups whose interest or expectations are impeded by organizational policies and strategies will encourage, through their collective actions, dysfunctional outcomes. This equally asserts their degree of informality which was earlier mentioned. Therefore, the informal structures are empowered enough to either support the formal routines or negatively act as an interference for a corporation.

Attention must be paid that a human being is not able to live without having social relations with others and that's why the informal organizations will appear after introducing formal routines. Hence, the most important strategy is to make alliance between individual and organizational goals and in this case, informal structures will have positive effects on the formal routines.

Negative impacts of informal organizations will arise when the employees are not satisfied with their work and do not feel fair in their wages and rewards. In this case, some employees form informal organizations and mix the real news with rumors to fight with the top-management strategies.

The organization development is a vital exercise that must be carried out with a successful conclusion if technological bondage is to be avoided in the nation. In our society today there is need for adopting a creative approach for our technological take off. The reason is to encouraged employees to cultivate the ability of making maximum use of resource available to them, develop new ways of resources utilization that may come in the course of their job.

Since Nigeria independence, the nation has gone through a gradual rise in the level of industrialization and the evolution of both small and complex organization. An organization as defined by Griffin (2007) is a combination of people, or human efforts, working in pursuit of certain common purposes called organization goals. It is any group of two or more people working to achieve a goal or goals.

As a matter of fact, there are potential benefits to be tapped from the existence and activities of the informal groups. The management can only tap the benefits when it is willing to work with them effectively without engaging in measures to suppress the informal organization.

While these multi perspective remains, the need to establish an empirical link between informal groups and performance is imperative, therefore, this study is aimed at showing the relationship between informal group dynamics and performance.

\subsection{Statement of the Problem}

Management of organizations has been trying to improve individual productivity through researches and product development, employment of high skilled and experienced workers. Despite these efforts, productivity is declining in an organization who is to be blamed is still declining or has remained low and unimpressive.

What is actually responsible for the continuous decline in productivity despite serious efforts by the management, who have control over these group is yet to be achieved from the above assertions, it become imperative or necessary to research and conduct an assessment on the impact of informal groups on organizational performance.

Informal groups exist in every organisation characterized by people as this is the interlocking structure that governs and influences how people interact at the work place to get the goals and the objectives of the organisation accomplished. This research is therefore investigating the impact of informal groups on organizational performance.

Expanding the knowledge frontiers and understanding of work place actions and inaction that are incentives to system functionality has been heightened than ever before. The reasons are not farfetched; competitiveness has attained a phenomenal level that if not strategically and holistically driven by managers might create an entropic state for organization. Similarly the inmate behavioral expression are seemingly assuming prominence in employee day by day involvement in organizational activities and their 
consideration as strategic resource requires that all such behavioral niceties should be given in depth analysis with a view to creating understanding and eventual decision making.

It is also important that the evolving nature of the construction sector should be viewed rigorously especially the socio-technical forms that are likely to propel functional outcomes especially in the light of the huge resources that are committed by operators in the sector.

\subsection{Objectives of the Study}

The general purpose of the study is to examine the impact of informal groups in organizational performance. Specifically, the objective aimed is as follows:

i. To identify why employees engage in informal groups

\subsection{Research Hypotheses}

The study will be conducted with the help of the following alternate hypothesis:

$\mathrm{H}_{1}$ : $\quad$ Employees engage in informal groups to gain self-confidence

\subsection{Research Method}

This research therefore covers three selected construction firms in Abuja, namely Nahman Construction, Arfo Construction Company and Julius Berger Nig. Plc., Abuja. Secondary data were obtained through books, journals, and internet. Empirical works of other scholars were consulted. A simple size of 319 was obtained from the population of 1,573 at 5\% error tolerance and 95\% degree of freedom using Yamane's statistical formula $319(100 \%)$ of the questionnaires distributed $304(95.3 \%)$ were returned and $15(4.7 \%)$ were not returned. The questionnaire was designed in Likert scale format. The researchers conducted a pretest on the questionnaire to ensure the validity of the instrument. Pearson's Product-Moment Correlation Coefficient was used to test the hypothesis

\subsection{Literature Review}

\subsubsection{Conceptual Framework on informal Group}

Groups are an important factor of organisational life in that the entire organisation and its sub- units are made up of groups of people who must cooperate in order for work to be done. Formal and informal groups exist in organisations and have a particular role to play, therefore an understanding of the nature of groups is vital if managers and leaders are to influence the behaviour of people in the work or organisational situation. Managers and leaders must be aware of the impact of these groups: formal ones are created to achieve specific organisational objectives, while informal groups emerge naturally within the organisation and serve to satisfy psychological and social needs of its members (Mullins 2010).

A group is constituted when two or more people come together and interact interdependently to achieve a common goal. Most of the definitions from various sources appear to have the following common characteristics: two or more people who are psychologically aware of each other and who interact to fulfill a common goal. These four basic conditions in the previous paragraph must be fulfilled to qualify a gathering or a collection of people as a group. Therefore a group is more than just a simple collection of people (Mullins, 2010). Membership to a group implies that individuals accept conditions and abide by the rules of the group. The rules are clearly defined by values, attributes and behaviours.

We face with many different group types within the organization. Those are Formal, Informal, Task and Control Group Types, Interest and Friendship Groups. When we briefly describe the subject (Robbins and Judge, 2010);

i. Formal Group means that the group is formed by the organization and the limits of subject, which the group will discuss, are determined.

ii. Informal Group means the groups that are formed in order to meet the social needs and their goals are not determined.

iii. Control Group means the group which is under the responsibility of a manager and the individuals account before the manager only. The example is the manager, responsible for the financial affairs department, and his/her staff working under his/her responsibility.

iv. Task Group means the group which is formed in order to perform the tasks that are determined by the organization. In order to accomplish the goal, the group may have the cross-control relations. If 
the crime is committed or there is a fault in the institution, then other units should also work in coordination with each other.

v. Interest Group means the group formed by the individuals who are interested in the certain subjects.

vi. Friendship Group means the group which is formed by the individuals who become close to each other, are interest in the same subjects, and find the many lowest common denominators.

\subsubsection{Reasons of Becoming the Member of a Group}

As well as the groups formed with the sense of mission, there are groups which are formed randomly. All individuals in the society are the members of a group somewhat. The individual already becomes the member of a group instinctively once he/she is born; so, the individual already begins to act with the sense of some responsibilities which the society that he/she takes place needs. As the individual gets away from the sense of loneliness upon becoming the member of a group, it helps to him/her to gain his/her selfconfidence.

The achievements, gained collectively by the group members, add many values to the group members such as recognition, recognition socially, obtaining the certain statutes. In this regard, the individual lives as the member of certain groups by the effects of certain belief, attitude and norms from the birth. The real reason of which the individual would like to be the member of a group is that he/she feels intimacy to that group and has the several common characteristics with individual's belief (Schien, 2010).

General Features of Groups In order to organize the groups, the features of group leadership, authority, communication, and socio-metric structure should be available. It is important to know those features in order to analyze the reasons of group behaviors. The leaders, who know those features, may manage the group productively.

T.R. Mitchell studied the group factors with a model, and examined the personal, situational and group structure characteristics. He discussed the group structure and processes in the work. The subjects such as group norms, role and statute relations, observance behavior that are the features of group structure. The group processes consist of the processes of group-in and group-out communication, conflict, decisionmaking and leadership. The brief descriptions of those processes are provided below:

a. Group Processes Stage: Carrying out all intergroup activities is provided via communication. The individuals obtain the in-group behavior rules and all solution ways through this way.

b. Conflict Stage: It is a factor which prevents the individual and group activities. Furthermore, the conflict is not always the negativity, but leads to the certain developments.

c. Decision-making Stage: It is defined as the group's correct and efficient decision-making process. Shaw (2007) found that the groups were more influenced by the decisions taken by the group than individually and that the ideas, filtered by many individuals, were noticed fast, even if they were faulty and less error was made in his work.

d. Leadership Stage: The leaders are the representatives of a group, and the individuals who protect the group's interests and provide the group's solidarity and affect the individuals and direct their activities by keeping them together.

General Functions of Group Psychological, Individual Functions The role of group is important regarding the meeting of individual's needs in participation of individuals in the groups. When it is discussed in this regard, it may be said that the group satisfies, first, its need (Levi, 2010).

For example, the needs of belonging, in other words, the needs of friendship, support and love are the needs that can be satisfied upon becoming the member of a group. An individual, becoming the member of tennis club, decides to become the member of this group, since he/she likes the people whom he/she meets there or needs to become friend with the new people as well as would like to play tennis.

On the other hand, it may also be said that the groups are the means of developing, strengthening or verifying the sense of identity of the individual and of maintaining his/her self-esteem. The individual may develop some emotions regarding who he/she is or may verify it, gain a status and may increase his/her selfesteem through his/her group membership. In the above example, if becoming the member of a tennis club is a status symbol of an individual, then the group performs an important function regarding the satisfaction of such need.

The groups are the means of determining the facts and solving the problems. There are some researches showing that the groups may take the more correct and doughtier decisions than the individuals in solving the problems that they face with. According to the results obtained from those researches, the groups may reach to more correct solutions than the individuals. Occurrence of incorrect ideas in the group fast, noticing 
the faults faster may be one of the reasons of it. Even if the individual doesn't see his/her fault, then other group members may see it.

The problems are more revised in the groups and thus, they don't make more faults than the individuals. For some individuals, the group is a shelter that he/she takes shelter in order to avoid the risky environment. With this feature, the group becomes a mean which increases the security against a common and powerful enemy or the threat and creates the sense of strength (Levi, 2010).

\subsubsection{Formal and Organisational functions}

The formal functions are the functions which are assigned to the group and the group is officially responsible for. The groups have the certain functions related to accomplishing the principle goals in the organizations and the groups operate in this direction and perform some formal functions (Schein, 2010). Multi-directional or Complex Functions The groups are the goal in some cases and means in some cases for the individuals.

However, the relation or differentiation between the goal and mean, which are the fundamental reasons of participating in the group, may not be accepted sufficiently clear and significant. The group membership, which may be accepted as the mean initially, turns into the goal later. The individual, who participates in the group in order to satisfy his/her need that is not directly related to the group, maintains his/her membership after satisfying his/her need via group. In addition to this, it should be emphasized that the groups, assuming the formal work, also perform mostly the psychological functions and therefore, turn into a natural group (Robbins \& Judge, 2010).

When the individual has right to speak on his/her environment, and feels that he/she is recognized by the others, he/she will able to get rid of his/her troubles, and recognize the social reality surrounding him/her. The group needs the loyalty of its members in order to function well. The group members always seek the opportunity to participate in the group and to develop during the life of group (Hunter et al, 2010).

\subsubsection{Organisational design}

Every organisation is composed of a system of interrelated jobs. The organisation structure comprises of a network of interconnections and interdependencies among different people and tasks that make up an organisation. An organisational structure enables the people within it to work together, thereby accomplishing things beyond the abilities of un-organised individuals.

Organisations are designed in layer form there is senior, middle and lower management or the executive, national, regional and local leadership. The determination of policy, decision-making, the exercise of authority and responsibility, and the execution of work are carried out by different people at different levels of seniority throughout the organisation structure. The design of an organisation is an exercise in matching structures, systems, styles of management and the people employed, to the various activities of the organisation. If there is a mismatch, then problems can arise (Mullins, 2010).

Traditionally, some managers were entrusted with the responsibility of setting the strategic direction and objectives for the organisation while middle managers were expected to implement this strategy. The divide appears when middle manages complain that their seniors are solely concerned with short-term financial results, while senior management assure that the middle management devotes more effort to voicing problems than to finding solutions (Mullins, 2010).

The divide, Mullins (2010) argues, deepens as each level accuses the other of pursuing its own personal rather than organisational ends. Middle management accuses senior managers of being concerned with their own career advancement, while senior management accuses middle management of directing their efforts to protecting their positions.

\subsubsection{How Informal Groups within Formal Organizations Boost Performance}

Although informal organizations create unique challenges and potential problems for management, they can also boost performance in the formal organization. They may contribute positively to the smooth functioning of a formal organization. In a formal organization where rigidity of its rules sometimes occurs, informal relationship has frequently been instrumental if not helpful in overcoming the obstacle and easing the workflow. 
For instance, a personal relationship between an employee and his superior will result in greater cooperation between them. It will also help create satisfaction, fulfillment and stability among employees in the organization. Communication between the various units of the organization will be expedited. An opening for strain, frustrations and dissatisfaction of the human resources in the organization which is a necessity will be created.

Through the grapevine, informal groups are able to keep their members informed on what administrative actions, policies, processes and standards that affect them. An awareness of managements' intended actions, policies, processes and standards enables employees to position themselves strategically to effectively execute tasks expected of them. When employees are strategically positioned, then they become more able to perform better.

Informal groups also help lighten management workload. Managers become less inclined to check up on workers when they know the informal organization is cooperating with them. This encourages entrustment, delegation, transference, decentralization and greater worker support of the manager, which suggests a probable improvement in performance and overall productivity. Informal relations act as a safety valve and fill the gap of managerial abilities. For instance, if a manager is weak in financial planning and analysis, a subordinate may informally lend a hand in preparing reports and assist the manager by either suggestions or direct involvement. This eventually will result in effective performance of tasks.

The informal group also provides a means for relieving emotional and psychological pressures (such as frustration, tension, and emotional problems) with management and other employees by allowing a person to discuss them among friends openly and candidly. Employees who through informal groups get rid of these emotional and psychological pressures have free minds to imagine and generate new ideas, concentrate and approach their duties with clear unambiguous thoughts and therefore perform better.

Informal groups in organizations encourage managers to prepare, plan, organize, and control in a more professional fashion. Managers who comprehend the power of the informal organization recognize that it is a check and balance on their use of control and authority. As a result, management with more careful thought and consideration, knowing that the informal organization can easily kill a poorly planned project, introduces changes and projects.

\subsubsection{Organizational Performance}

The organization performance literature is robust with multi-perspectives. These perspectives are however expected when viewed in the light of the multi-disciplinary and functional make-up of organizations. They have essentially described performance in line with their functional expectations.

All the same, these have not shifted from a common conceptual thinking that, performance relates to expected and desired outcomes resulting from aggregate activities, roles, responsibilities and functions carried out by organization through her workforce. Importantly, while the conceptual rage lasts, Kaplan \& Norton (2012) have provided a more embracing framework that have assisted and channeled the debate on performance measures. Their framework provides a functional guide that permits the definition of measures based on functional areas. In line with extant position, this study performance measures are process oriented measures which are non-financial. From the extensive review of the theoretical context, the study has used innovativeness and responsiveness as measures of performance.

\subsection{Test of Hypothesis}

\section{Hypothesis one}

$\mathrm{H}_{\mathrm{o}}$ : Employees do not engage in informal groups to gain self-confidence

$\mathrm{H}_{1}$ : Employees engage in informal groups to gain self-confidence 
Table 1: Descriptive Statistics

\begin{tabular}{|l|l|l|l|}
\hline & Mean & $\begin{array}{l}\text { Std. } \\
\text { Deviation }\end{array}$ & $\mathrm{N}$ \\
\hline $\begin{array}{l}\text { Informal } \\
\text { groups } \\
\begin{array}{l}\text { Self- } \\
\text { confidence }\end{array}\end{array}$ & 1.8261 & 1.16043 & 304 \\
\hline
\end{tabular}

Table 2: Correlations

\begin{tabular}{|c|c|c|c|}
\hline & & mission & $\begin{array}{l}\text { customer } \\
\text { loyalty }\end{array}$ \\
\hline \multirow[t]{3}{*}{$\begin{array}{l}\text { Informal } \\
\text { groups }\end{array}$} & $\begin{array}{l}\text { Pearson } \\
\text { Correlation }\end{array}$ & 1 & \\
\hline & Sig. (2-tailed) & & .000 \\
\hline & $\mathrm{N}$ & 304 & 385 \\
\hline \multirow[t]{3}{*}{$\begin{array}{l}\text { Self- } \\
\text { confidence }\end{array}$} & $\begin{array}{l}\text { Pearson } \\
\text { Correlation }\end{array}$ & $.955^{* *}$ & 1 \\
\hline & Sig. (2-tailed) & .000 & \\
\hline & $\mathrm{N}$ & 304 & 304 \\
\hline
\end{tabular}

**. Correlation is significant at the 0.01 level (2-tailed)

Table (1) shows the descriptive statistics of the informal groups via, self-confidence with a mean response of 1.8261 and std. deviation of 1.16043 for informal groups and a mean response of 1.9065 and std. deviation of 1.26713 for self-confidence and number of respondents (304). By careful observation of standard deviation values, there is not much difference in terms of the standard deviation scores. This implies that there is about the same variability of data points between the dependent and independent variables.

Table (2) is the Pearson correlation coefficient for informal groups and self-confidence. The correlation coefficient shows 0.955 . This value indicates that correlation is significant at 0.05 level (2tailed) and implies that there is a significant positive relationship between informal groups and self-confidence $(\mathrm{r}=.955)$. The computed correlations coefficient is greater than the table value of $r=.195$ with 383 degrees of freedom $(\mathrm{df} .=\mathrm{n}-2)$ at alpha level for a two-tailed test $(\mathrm{r}=.955, \mathrm{p}<.05)$. However, since the computed $\mathrm{r}=.955$, is greater than the table value of .195 we reject the null hypothesis and conclude that there is a significant relationship between informal groups and self-confidence in Nigeria construction firms $(r=.955, \mathrm{P}<.05)$.

\section{Discussion of Results}

The Hypothesis was tested using Pearson product moment correlation coefficient to identify why employees engage in informal groups to gain self-confidence $(r=.955, \mathrm{P}<05)$. The null hypothesis was rejected and the alternate hypothesis was accepted resulting in the conclusion that there is a significant relationship informal groups and self-confidence in Nigerian construction firms.

\subsection{Conclusion}

This study on "Impact of informal groups on organizational performance" is very timely and unequivocally relevant, considering particularly the recent drive in the country to ensure the revitalization of the ailing construction firms in Nigeria. Various policies have been formulated to ensure the growth of this sector, and various strategies are being put in place and implemented to ensure its success. Albeit, an important aspect 
that would go a long way in ensuring that these policy and strategy formulations have the desired effect on the construction firms in Abuja, Nigeria, is being able to handle the outcomes that these changes (policies and strategies) will present.

There exist several plausible discussions on informal grouping with many expressing dysfunctional implications. This aspect of the discourse have pervaded the thinking on informal groups which are largely seen as perpetuating group interest at the expense of the organization that provides the playing ground. In this vein this study primarily investigated the link between informal group's dynamics and performance of firms in construction sector. From the data obtained and analyzed what is clear is that, the informal group dynamic components social interaction behavior, knowledge enrichment behavior, value reinforcement behavior and member mentoring behavior are critical to the overall performance of this sector. Their strategic implication is underscored in their ability to strongly relate with performance in terms of innovativeness and responsiveness. They commonly fraternize to enrich their work content and share knowledge that ultimately enhances performance goals. What this holds for the organization is that managers/operators should allow a flexible work climate that encourage common basis for group as it will help build on the confidence they need to unleash their creative potential. Importantly, as firm strive to enrich their knowledge reservoir for competitive position; informal groups are proven facilitators of knowledge acquisition and sharing amongst group-members which is a likely necessity for knowledge enrichment. If literature position on mentoring as a means for capacity building is anything to go by, informal groups should be considered a veritable means by managers in organization to stimulate member mentoring which has long-term implication on organizational performance.

\subsection{Recommendations}

Based on the findings and result of this study, the following recommendations were made;

i. Informal groups approach should be adopted by construction firms as an integral concept within their organizations, particularly as interventionist strategy to improve performance.

ii. An effective informal group should be built by applying practical skills/strategies to maximize organizational performance. These skills/strategies should include, but not limited to, getting to know the team, defining the group's purpose, establishing norms, encouraging questions, celebrating accomplishments and being participatory and assessing organizational effectiveness.

iii. Informal group members should interact with one another in order to understand their weaknesses and strengths, by doing so, they will build trust and support for each other, which will make their team more cohesive.

iv. It is also recommended that organizational incentives and rewards should be strictly adhered to in other to boost team performance and effectiveness.

v. Informal group's members should be carefully selected so that members with requisite skills are selected to work towards achieving the required group objectives.

vi. Reduction in resistance can be achieved in many ways; proper communication, patience and tolerance are also required to help people in strong resistance to understand and accept the group norms.

vii. Managers of construction firms should swerve group members from time to time to inject new ideas into the group; they should also make available all the necessary resources required by group members to work optimally for them to achieve their objectives.

viii. Managers of construction firms should encourage employees to undergo constant training, development, workshops and seminars. This is to keep them abreast of current issues as it concerns their organizations, as such they will be proactive rather than reactive in dealing with challenges that might come up.

\section{References}

[1] Cross and Parker (2014), Leadership of Organisational Networks

[2] Griffin (2007), The persistence of structural priming: Transient Activation or Implicit Learning: Stanford University

[3] Gillas, O.J. (2007). Ethics and Groups: A Handbook on Workplace Ethics, Lagos: Gellaram Press. 
[4] Greenberg S. (2010), Organizational design strategy- A case study on a public Baccalaureate college. NSC Self Study. Available: http://www.nsc.nevada.edu/ PDF/NSCSelfStudy0607.pdf.

[5] Hunter, D., Thorpe, S., Brown, H., \& Bailey, A. (2009). The Art of Facilitation: The Essentials for Leading Great Meetings and Creating Group Synergy. Jossey-Bass; Revised Edition edition.

[6] Kaplan, R.S. \& Norton, D.P. (2012). Using the Balanced Score to Work.Journal of Business Review,9(10), 134-147.

[7] Levi, D. J. (2010). Group Dynamics for Teams. New York: SAGE Publications.

[8] Mullins L.J (2010), Management and Organisational Behaviour: Financial Times, Prentice Hall.

[9] Reitz, H. (2007). Behavior in Organizations. Illionis: R.D.Irwin Inc. Homevvood.

[10] Robbins, S. P., \& Judge, T. (2010). Organizational Behavior. New York: Prentice Hall.

[11] Schein (2010), Organisation and Management- Google Books

[12] Shaw, M. E. (2007). Group Dynamics: The Psychology of Small Group Behavior (3rd ed.). Montreal, Quebec: McGraw-Hill.

[13] Van Vianen, A.E.M.,\& DeDrew, C.K.W. (2011). Personality in Teams: Its Relationship to Social Cohesion, Task Cohesion, and Team Performance. European Journal of Work and Organizational Psychology, 10,97-120. 